\title{
Event related potentials from closed head injury patients in an auditory "Oddball" task: evidence of dysfunction in stimulus categorisation
}

\author{
M D RUGG,* C P COWAN, * M E NAGY,* A D MILNER, ${ }^{*}$ I JACOBSON, $\dagger$ \\ D N BROOKS $\ddagger$
}

\begin{abstract}
From the MRC Cognitive Neuroscience Research Group, ${ }^{*}$ University of St Andrews, the Department of Surgical Neurology, Dundee Royal Infirmary, $\dagger$ and the Department of Psychological Medicine, University of Glasgow $\ddagger$ $U K$
\end{abstract}

SUMMARY Event-related potentials (ERPs) were recorded from 19 closed head injury (CHI) patients, at least 6 months after injury, and an equal number of control subjects, during a task requiring the covert counting of rare auditory "target" stimuli against a background of frequent "non-targets". In both groups, ERPs to targets contained enhanced frontal N2 and parietal P3 components. N2 was larger in amplitude in the CHI patients than in the controls, and its peak latency was delayed. P3 amplitude was smaller in the patients, but its latency was not significantly different from that of the control group. The delay in N2 latency is interpreted as evidence of an increase in the time needed to achieve stimulus categorisation in $\mathrm{CHI}$ patients. The larger $\mathrm{N} 2 \mathrm{~s}$ in this group are thought to reflect the additional cognitive effort required after $\mathrm{CHI}$ to cope with the task. The negative findings with respect to P3 latency suggest that this may be a less sensitive measure of information-processing efficiency in this task than the latency of $\mathrm{N} 2$.

Individuals who suffer a closed head injury (CHI) often demonstrate one or more of a characteristic range of cognitive dysfunctions. These include depressed intellectual performance, ${ }^{1-3}$ poor long-term memory, ${ }^{45}$ and poor performance on tasks requiring speeded processing and decision making, as for example in the cases of 4-choice reaction-time ${ }^{67}$ and paced auditory serial addition. ${ }^{89}$ Although these sequelae are well known, there has been little attempt to relate them to indices of cerebral function such as scalprecorded event-related potentials (ERPs). ERPs are an attractive means of investigating closed head injury because of their "real-time" nature, and the fact that they are sensitive to a range of cognitive variables. They therefore offer a means of assessing information-processing efficiency independently of overt behavioural measures, and in particular, they provide a relatively direct way of investigating "early" stages of information-processing. Moreover, by determining the distribution on the scalp of ERP

Address for reprint requests: M D Rugg, MRC Cognitive Neuroscience Research Group, Department of Psychology, University of St Andrews, St Andrews, Fife KY16 9JU, UK.

Received 4 August 1987 and in revised form 25 November 1987. Accepted 4 December 1987 differences occurring as a consequence of experimental or group (such as patient vs control) variables, hypotheses about the brain regions responsible for the manifestation of these differences can be formulated.

In the present paper, we report the results of one of a number of scalp-recorded electrophysiological procedures which we are using to investigate the effects of CHI. This is the auditory "oddball" procedure, in which subjects must detect and keep a running count of occasional rare "target" stimuli occurring against a background of more frequent "non-targets". As has been demonstrated in many studies (for reviews see refs 10,11 ), the event-related potentials (ERPs) elicited by rare stimuli in the oddball paradigm are differentiated from the ERPs to frequent stimuli by the enhancement of a fronto-central negative peak (N2), ${ }^{*}$ and a subsequent parietally-maximum positive

\footnotetext{
*A variety of negative ERP components occur in the N2 latency range. ${ }^{13}$ In the auditory modality, it is possible to dissociate an "N2a" (also known as "mismatch negativity") from a later, more frontally distributed "N2b". The former component is characterised by its responsiveness to low probability "deviant" stimuli even when the subject is not attending to the stimulus train, whereas the latter seems to be associated with the allocation of attention to the eliciting stimulus. In the oddball task, when the subject is attending to all stimuli, it is possible that the fronto-central "N2" wave is a composite of N2a and N2b components, which overlap in time and scalp distribution.
} 
wave (P3). These probability-sensitive ERP components are thought to reflect important (and somewhat overlapping) aspects of information-processing. The fronto-central N2 wave has been interpreted as a sign of effortful, "controlled" stimulus processing, with a peak latency which correlates with the time taken to categorise the eliciting stimulus. ${ }^{12-14}$ The amplitude of the parietal P3 to auditory "oddballs" appears to be under the control of the combination of the probability, "task relevance" and informational value of the eliciting event, ${ }^{11} 15$ and has been the subject of intensive experimental investigation for around two decades. Of particular interest is the finding that the peak latency of this component appears to correlate well with the time required to categorise stimuli, but is relatively insensitive to factors (such as motor preparation and stimulus-response compatibility) which affect reaction time by influencing response selection and execution. ${ }^{16} 17$ The precise cognitive processes with which the $\mathbf{P} 3$ is associated have however yet to be identified.

In view of the fact that $P 3$ is a robust, easily measured ERP feature, which can be elicited in relatively simple and undemanding experimental paradigms, it seems likely to be useful in the investigation of clinical populations. In particular, P3 may be a useful indicator of general cognitive function, in that a lengthening of its latency may signal a slowing of the processes involved in stimulus evaluation and categorisation. To the extent that CHI patients' deficits on speeded decision-making tasks reflect a slowing of these processes, $\mathrm{P} 3$ latency in this population would therefore be expected to be prolonged. This finding, along with a decrement in P3 amplitude, has indeed been reported, ${ }^{18-20}$ and one of the aims of the present study was to investigate its generality.

In addition to the $\mathrm{P} 3$ component, we were interested in examining N2 in CHI patients. Although preceding the $\mathbf{P} 3$ in time, and considered also to reflect the duration of stimulus categorisation processes, this component has received relatively little attention in studies of neurological dysfunction. A notable exception is Curry's ${ }^{19} 20$ study of CHI patients. Using an auditory detection task of somewhat greater complexity than the oddball procedure, Curry observed an enhancement in amplitude, and a prolongation in latency, of this fronto-centrally distributed component. The present study therefore investigated the effects of CHI on two putative ERP indices of speed of information-processing, the N2 and P3 components, allowing an assessment of the relative sensitivity of these two ERP measures in discriminating CHI patients from controls. Performance on a simple behavioural measure of information processing (4-choice reaction-time) was also assessed, affording the opportunity to investigate whether these ERP components are in any way predictive of performance on an overt measure of information processing efficiency.

\section{Method}

Patients and controls Nineteen patients (2 female) were studied, all of whom had suffered a CHI 6 months or more prior to testing. All fulfilled one or more of the following criteria: (1) Glasgow coma scale on admission to hospital of 8 or lower, (2) presence of an intra-cerebral haematoma, (3) post-traumatic amnesia (PTA) of $\mathbf{4 8}$ hours or more. Characteristics of the patient group are summarised in table 1 .

Table 1 also summarises the details of the control group. This also consisted of 19 individuals (all male), who had been admitted to an accident and emergency unit, as a result of trauma excluding the head, at least 6 months prior to testing. None had any known history of $\mathrm{CHI}$.

As can be seen from table 1, the control group was reasonably well matched to the patients in terms of age and the vocabulary sub-test of the WAIS, a putative indicator of pre-morbid intellectual function. On other sub-tests, and on two of the three measures of memory function employed (Paired Associates Test of the Wechsler Memory Scale, and the Buschke Selective Reminding Test, ${ }^{21}$ the $\mathrm{CHI}$ patients performed, as a group, less well than the controls, showing the pattern of impairment typical of these patients. It should be noted, however, that the patient group was by no means homogeneous with respect to psychometric and neuropsychological test performance; a number of patients scored well into the normal range on some or all of the tests.

EEG recording EEG was recorded from nine scalp sites situated over the midline $(\mathrm{Fz}, \mathrm{Cz}, \mathrm{Pz})$ and homotopic regions of the left and right hemispheres [P3 and P4 (left and right parietal), T3 and T4 (left and right temporal), and $75 \%$ of the distance from Fz to F7 (left frontal) and F8 (right fontal)]. These channels were referred to linked mastoids in the first seven patients and eight controls tested, and to a balanced non-cephalic reference ${ }^{22}$ in all other subjects. ${ }^{*}$ EOG was recorded from a bipolar electrode pair situated just above the right eyebrow and on the outer canthus of the left eye. All channels were recorded with a bandwidth of $0.03-32 \mathrm{~Hz}$ ( $3 \mathrm{~dB}$ points), and sampled at a rate of $3 \mathrm{~ms}$ per point, starting $60 \mathrm{~ms}$ before stimulus onset and continuing for $708 \mathrm{~ms}$ thereafter.

Stimuli and task In the experimental run, 200 binaural tone bursts ( $80 \mathrm{~dB}$ SPL, $50 \mathrm{~ms}$ duration, $10 \mathrm{~ms}$ rise and fall times) were presented at a rate of 1 every $3 \mathrm{~s}$. One hundred and fifty three of these had a frequency of $250 \mathrm{~Hz}$ (non-targets), and $47 \mathrm{had}$ a frequency of $500 \mathrm{~Hz}$ (targets). These two types of tone were randomly intermixed and the same series was used with all subjects. The 200 stimuli were presented with a short break after the first 100 , and subjects were required to keep a running count of the number of targets presented in each half of the series, reporting their counts during the half-way break and at the end.

The subjects performed the task seated upright in a comfortable chair with their eyes open. They were instructed to

*The change of reference was prompted by a concern to achieve maximum sensitivity for the detection of ERP asymmetries. No feature of the ERPs recorded from midline electrodes differed as a consequence of type of reference, and the data have been pooled for the purposes of the present report. 
minimise blinking and body movement as much as possible, and to avoid counting the targets out loud. Twenty practice trials were given before the experimental run, and these were repeated as necessary if a subject did not initially comply with the experimental instructions.

Table 1 Characteristics of CHI patients and controls. Means (SDs in brackets) for age, number of years of education, WAIS subtests, and memory tests

\begin{tabular}{|c|c|c|}
\hline & Patients & Controls \\
\hline $\begin{array}{l}\text { Age (yrs) } \\
\text { Years of full-time } \\
\text { education }\end{array}$ & $\begin{array}{l}25 \cdot 74(8.75) \\
12.47(1.86)\end{array}$ & $\begin{array}{l}27 \cdot 32(9 \cdot 27) \\
13.03(2 \cdot 52)\end{array}$ \\
\hline $\begin{array}{l}\text { WAIS (Age Scaled Scores): } \\
\text { Vocabulary } \\
\text { Similarities } \\
\text { Object assembly } \\
\text { Digit symbol }\end{array}$ & $\begin{array}{r}9 \cdot 21(2 \cdot 35) \\
8.42(2 \cdot 12) \\
11 \cdot 56(2 \cdot 50) \\
6 \cdot 37(2 \cdot 22)\end{array}$ & $\begin{array}{l}10.58(2 \cdot 63) \\
10 \cdot 21 *(2 \cdot 76) \\
13.47(3.82) \\
10.00 \pm(3.04)\end{array}$ \\
\hline $\begin{array}{l}\text { Weschler associate learning } \\
\text { (Sum of Hard and } \\
\text { Easy pairs) }\end{array}$ & $13 \cdot 34(4 \cdot 73)$ & $15.92+(2 \cdot 15)$ \\
\hline $\begin{array}{l}\text { Buschke selective } \\
\text { reminding (Total Recall) }\end{array}$ & $91 \cdot 74(25 \cdot 75)$ & $112 \cdot 5 *(33 \cdot 36)$ \\
\hline $\begin{array}{l}\text { Rey complex figure: } \\
\text { Copy } \\
\text { Recall }\end{array}$ & $\begin{array}{l}33.53(2.80) \\
21.68(6.93)\end{array}$ & $\begin{array}{l}34.55(2.14) \\
25.74(6.84)\end{array}$ \\
\hline
\end{tabular}

${ }^{*} \mathrm{p}<0.05$.

$+\mathrm{p}<0.01$.

$\pm \mathrm{p}<0.001$.
ERPs ERPs elicited by target and non-target tones were formed by on-line averaging from each recording channel. Trials on which electro-oculographic activity exceeded a preset criterion were automatically rejected from the averages. 4-Choice RT Task On the same day as the ERP recording, the patients and controls performed a 4-choice reaction time task. ${ }^{6}$ This is a self-paced task in which subjects must move the index finger off a push-button to depress one of a radial array of four similar buttons situated in front of the start position. Each of these buttons had a small light-emitting diode (LED) just above it, and the subject was required, on each trial, to depress the button adjacent to the illuminated LED as quickly as possible. A trial began when the central "start" button was depressed by the subject. One second after this a warning tone was delivered, and $1 \mathrm{~s}$ later a randomly selected LED was illuminated. One hundred trials were performed, preceded by 25 practice trials.

\section{Results}

The mean number of trials contributing to subjects' ERP waveforms to the targets was $41 \cdot 7$ (minimum = 25) for the CHI patients, and 43.9 (minimum $=28$ ) for the controls. The grand average waveforms from the patient and control groups are shown in fig 1 for all electrode sites, and fig 2 illustrates overlayed target and non-target waveforms from all members of each

\section{Control}
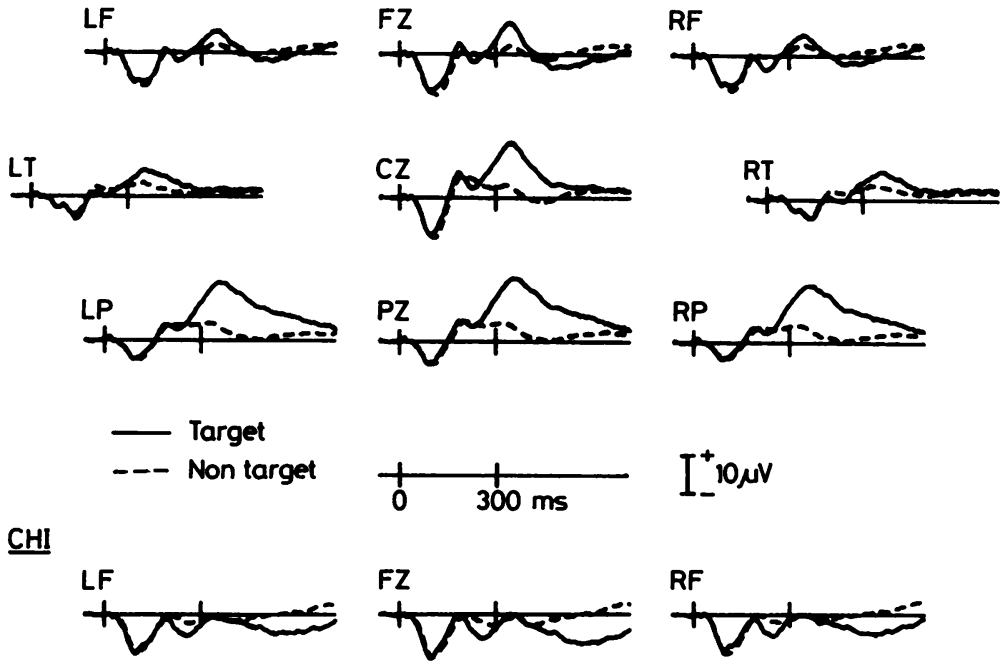

CHI
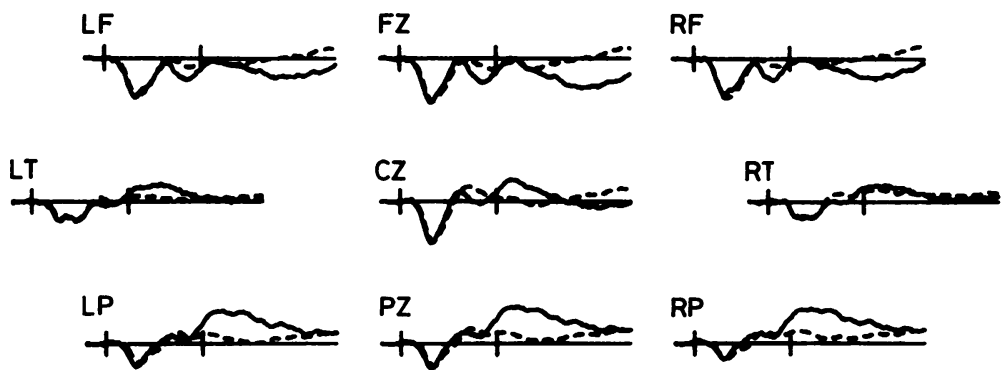

Fig 1 Grand-average target and non-target ERP waveforms of the CHI patients (lower half) and control group (upper half), from all electrode sites. 


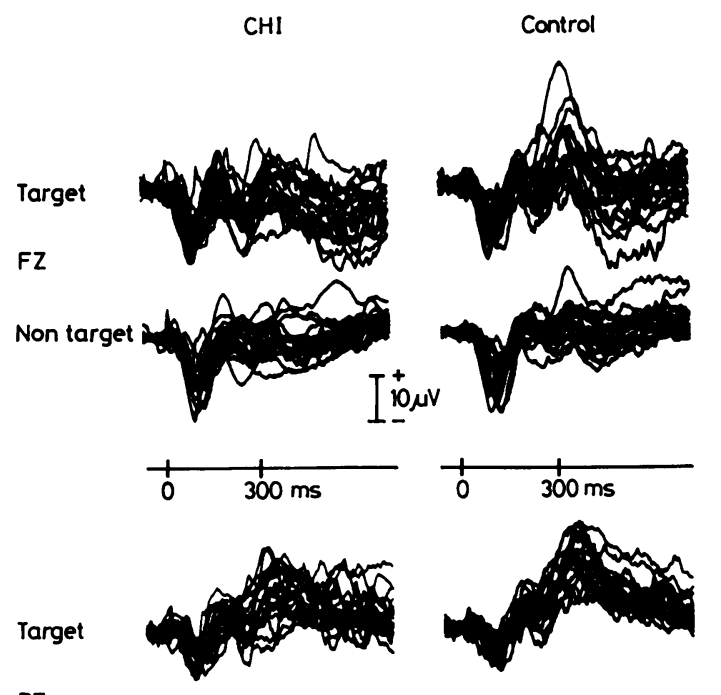

PZ

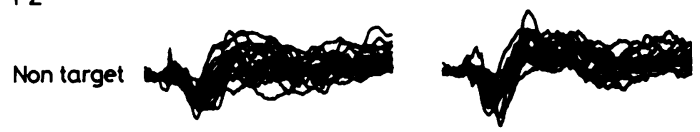

Fig 2 ERPs from $\mathrm{Fz}$ and $\mathrm{Pz}$ electrode sites from each member of the CHI and control group, overlayed separately for target and non-target stimuli.

Table 2 NI amplitude (microvolts) for the midline electrode sites from CHI patients and controls for target and non-target stimuli

\begin{tabular}{|c|c|c|c|}
\hline & $F Z$ & $C Z$ & $P Z$ \\
\hline \multicolumn{4}{|l|}{ Patients } \\
\hline Targets & $\begin{array}{c}-13 \cdot 11 \\
(3.25)\end{array}$ & $\begin{array}{c}-12 \cdot 38 \\
(2.72)\end{array}$ & $\begin{array}{c}-7.97 \\
(2.38)\end{array}$ \\
\hline Non-targets & $\begin{array}{r}-13 \cdot 11 \\
(4 \cdot 31)\end{array}$ & $\begin{array}{r}-12 \cdot 08 \\
(4 \cdot 15)\end{array}$ & $\begin{array}{r}-7.06 \\
(2.77)\end{array}$ \\
\hline \multicolumn{4}{|l|}{ Controls } \\
\hline & $\begin{array}{r}-11 \cdot 37 \\
(4 \cdot 28)\end{array}$ & $\begin{array}{r}-11 \cdot 20 \\
(4 \cdot 15)\end{array}$ & $\begin{array}{c}-7.01 \\
(2.77)\end{array}$ \\
\hline Non-targets & $\begin{array}{r}-12.15 \\
(5.24)\end{array}$ & $\begin{array}{r}-12.26 \\
(5.38)\end{array}$ & $\begin{array}{r}-7.22 \\
(3.64)\end{array}$ \\
\hline
\end{tabular}

group. It is evident from this latter figure that the across-subject variability of the waveforms is very similar in the two groups. A prominent frontalmaximum $\mathrm{N} 1$ is present in the waveforms from both groups. Following the N1, target/non-target differences are evident, taking the form of an enhancement of a frontally distributed N2 component peaking at approximately $250 \mathrm{~ms}$, and a parietally-maximum P3, with a latency of approximately $360 \mathrm{~ms}$. Preliminary analyses revealed that no additional information about group differences was obtained by incorporating amplitude measures from lateral as well as midline electrodes, and in the analyses that follow, comparisons across electrodes are restricted to the three midline sites, that is, $\mathrm{Fz}, \mathrm{Cz}$, and $\mathrm{Pz}$. Amplitudes were measured with respect to the mean of the $60 \mathrm{~ms}$ prestimulus baseline. All ANOVAs are based when appropriate on the Greenhouse-Geisser correction for inhomogeneity of covariance for repeated measures, ${ }^{23}$ and $\mathrm{F}$ ratios are reported with corrected degrees of freedom.

NI N1 latency did not discriminate CHI patients and controls, but was slightly longer in both groups for non-targets compared with targets $(\mathrm{F} 1 / 36=13 \cdot 39$, $\mathrm{p}<0.001$ ). N1 latencies at $\mathrm{Cz}$ (with standard deviations) were $97(11.5) \mathrm{ms}$ and $109(13.4) \mathrm{ms}$ in the case of targets and non-targets in the patients, and 96 $(11.7) \mathrm{ms}$ and $103(14.4) \mathrm{ms}$ in the controls.

N1 amplitudes are shown in table 2. As in the case of $\mathrm{N} 1$ latency, these data did not discriminate $\mathrm{CHI}$ patients and controls. ANOVA gave rise to a significant effect of electrode site (F1.4/48.8 $=115 \cdot 4$, $\mathrm{p}<0.0001$ ), reflecting a fronto-central distribution for this component. In addition, the interaction between condition and electrode site just attained significance $(F 1 \cdot 3 / 45 \cdot 3=3.78, \quad p<0.05)$. This reflected a tendency, across groups, for $\mathrm{N} 1$ to be slightly larger in the non-target condition at $\mathrm{Fz}$ and $\mathrm{Cz}$, but slightly smaller at $\mathrm{Pz}$.

$N 2$ The $\mathrm{N} 2$ was most clearly evident at $\mathrm{Fz}$ and in response to target tones. In many subjects' records it proved impossible to identify a clear N2 peak at more posterior electrodes or in the non-target condition. Therefore only the latency values associated with target tones were subjected to analysis. N2 amplitude for each subject was quantified by measuring the mean amplitude of the waveforms from the three midline electrodes in a latency window extending $\pm 12 \mathrm{~ms}$ from the $\mathrm{N} 2$ peak identified at $\mathrm{Fz}$ in the target condition.

Mean N2 latency was $262(20 \cdot 7) \mathrm{ms}$ for CHI patients, and $239(21.0) \mathrm{ms}$ for the controls; the $23 \mathrm{~ms}$ difference between these means was significant ( $\mathrm{t} 36=$ $3.49, \mathrm{p}<0.005)$. These latencies are plotted for each subject in fig 3 .

N2 amplitudes are shown in table 3. ANOVA revealed significant effects for group $(\mathrm{F} 1 / 36=6 \cdot 24, \mathrm{p}$ $<0.025)$, target $/$ non-target condition $(\mathrm{F} 1 / 36=$ $15 \cdot 11, \mathrm{p}<0.0001)$, and electrode site $(\mathrm{F} 1 \cdot 6 / 56 \cdot 4=$ $99.35, \mathrm{p}<0.0001)$. In addition, there were significant interactions between condition and electrode $(\mathrm{F} 1 \cdot 6 / 56.9=23.76, \mathrm{p}<0.0001)$, and between group, condition and electrode $(\mathrm{F} 1 \cdot 6 / 56.9=3.81, \mathrm{p}<0.05)$. The effects involving electrode and condition reflect the frontal distribution of this component, and the fact that it was larger to targets, particularly at Fz. The group effects reflect the larger $\mathrm{N} 2 \mathrm{~s}$ found in the patients, in particular for targets at the Fz electrode. $P 3$ The latency of P3 to targets was assessed at Pz. In three patients it was impossible to identify an 

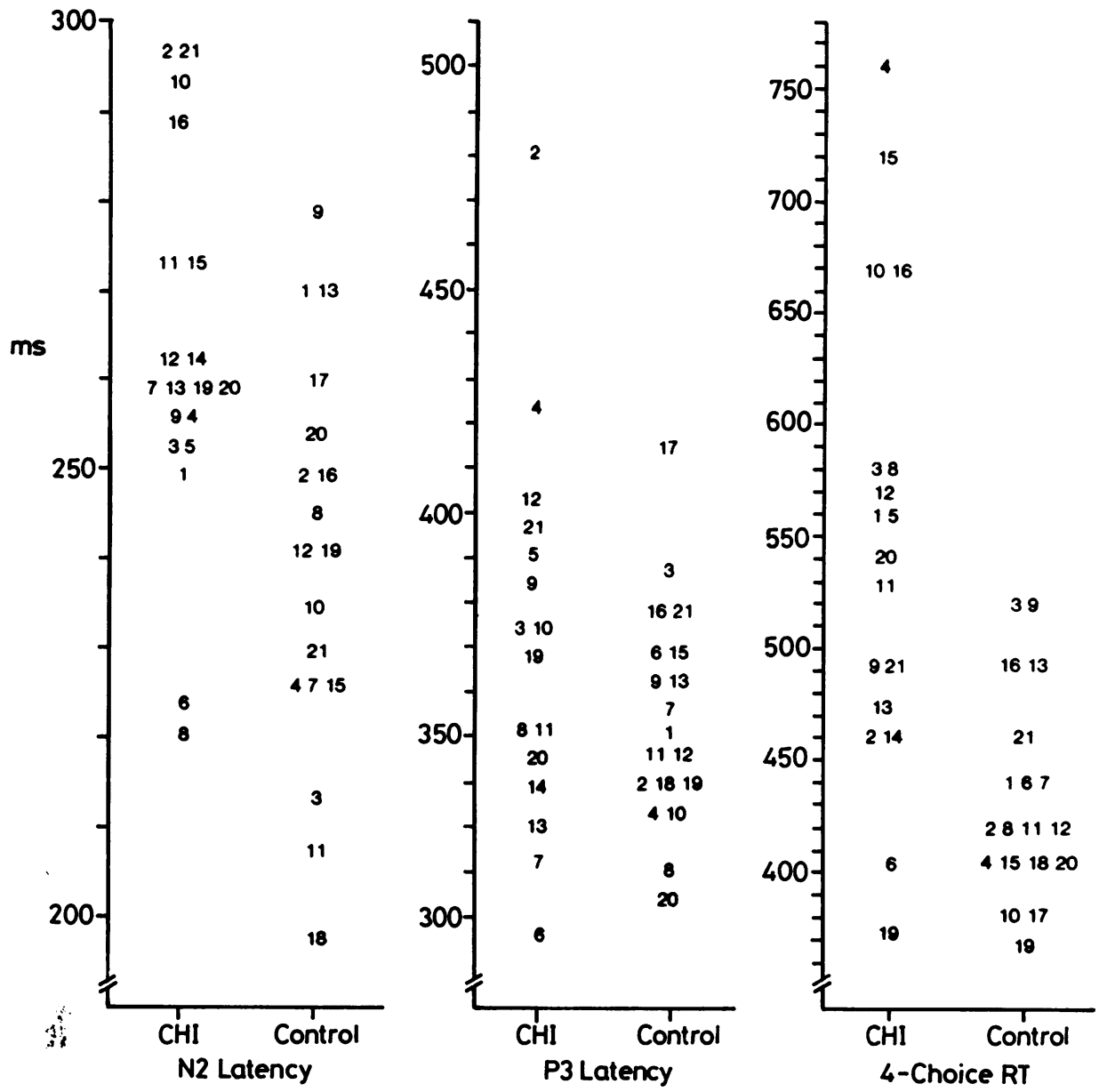

CHI PTA duration

7 days or less : 78912

8-14 days :561011131415161921

15-28 days : 123420

Fig 3 Values for each member of the CHI control groups on measures of N2 latency, P3 latency and 4-choice RT. Members of each group are identified by number, and those patients belonging to each of three categories of PTA duration are identified

unequivocal P3 peak, either because of multiple peaks, or because of a flattened, plateau-like waveform. These subjects were excluded from the analysis of the latency of this component.

Mean P3 latency from the $16 \mathrm{CHI}$ patients in whom it could be measured was $371(43.0) \mathrm{ms}$, compared to $357(22.8) \mathrm{ms}$ in the controls. The $14 \mathrm{~ms}$ difference between the groups did not approach significance $(t 21 \cdot 9=1 \cdot 19)$. (The variances of the two samples did differ significantly $(\mathrm{F} 15 / 18=3.56, \mathrm{p}<0.05)$; because of this inhomogeneity of variance $t$, and its associated degrees of freedom, were estimated using unpooled estimates of population variance, as suggested by Ferguson). ${ }^{24}$ The individual latency data are shown in fig 3 , where it can be seen that the data from the patient group contain an outlier (patient 2) whose P3 latency exceeds that of all other subjects by some $50 \mathrm{~ms}$. Exclusion of this patient's data markedly reduced the variability of $\mathrm{P3}$ latency among the patients $(\mathrm{SD}=$ 32.7).

The amplitude of $\mathrm{P} 3$ was measured by computing the mean amplitude of the region between $275-600 \mathrm{~ms}$ 
Table 3 N2 amplitude (microvolts) for the midline electrode sites for CHI patients and controls for target and non-target stimuli (measured as the mean amplitude of a $24 \mathrm{~ms}$ window straddling the peak latency of the target N2 at FZ)

\begin{tabular}{lccc}
\hline & $F Z$ & $C Z$ & $P Z$ \\
\hline Patients & & & \\
$\quad$ Targets & -7.46 & 1.39 & $2 \cdot 29$ \\
& $(4.44)$ & $(4.39)$ & $(4.94)$ \\
Non-targets & $-2 \cdot 58$ & 1.85 & $2 \cdot 68$ \\
& $(4.42)$ & $(5 \cdot 29)$ & $(4 \cdot 18)$ \\
Controls & & & \\
Targets & -2.98 & 2.42 & 3.93 \\
& $(4.36)$ & $(4.49)$ & $(3.82)$ \\
Non-targets & -0.46 & $4 \cdot 17$ & 4.52 \\
& $(3.13)$ & $(3.87)$ & $(3.16)$ \\
\hline
\end{tabular}

Table 4 Mean amplitude (microvolts) of the 275-600 ms latency region for $\mathrm{CHI}$ and control subjects, for target and non-target stimuli

\begin{tabular}{lccc}
\hline & $F Z$ & $C Z$ & $P Z$ \\
\hline Patients & & & \\
Targets & 4.09 & 2.63 & 7.50 \\
& $(4.73)$ & $(4.43)$ & $(4.52)$ \\
Non-targets & -1.58 & 0.50 & 1.95 \\
& $(2.89)$ & $(2.61)$ & $(2.56)$ \\
Controls & & & \\
Targets & 0.76 & 7.21 & 11.00 \\
Non-targets & $(6.36)$ & $(5.43)$ & $(3.96)$ \\
& 0.27 & 1.28 & 2.33 \\
& $(3.55)$ & $(2.89)$ & $(2.32)$ \\
\hline
\end{tabular}

post-stimulus, allowing those patients in whom no peak could be identified to contribute to the analysis. These data are shown in table 4. ANOVA gave rise to significant effects for group $(\mathrm{F} 1 / 16=7 \cdot 20, \mathrm{p}<$ $0.025)$, target/non-target condition $(\mathrm{F} 1 / 36=36 \cdot 17, \mathrm{p}$ $<0.0001)$ and electrode site $(\mathrm{F} 1 \cdot 2 / 42 \cdot 6=109.09, \mathrm{p}<$ $0.0001)$. The interactions between group and condition $(\mathrm{F} 1 / 36=8.67, \mathrm{p}<0.01)$ and condition and electrode site $(\mathrm{F} 1 \cdot 3 / 47 \cdot 3=83.24, \mathrm{p}<0.0001)$ were also significant. These effects reflect the increased positivity of this area of the waveforms in response to targets in both patients and controls, this target/non-target difference having a parietal maximum. The group by condition interaction reflects the smaller values of this measure in the patients' target, but not non-target, waveforms. An analysis was also performed on P3 peak amplitude data, obtained by measuring the amplitude at each midline site of a latency window extending $\pm 12 \mathrm{~ms}$ either side of the target P3 peak at Pz. This unequal N ANOVA (16 patients vs 19 controls) yielded an identical set of effects to those described for the 275-600 ms measure.

The mean number of targets counted by the $\mathrm{CHI}$ patients (summed across the two halves of the experimental run) was $47.9(2.9)$, compared with $47.0(0.5)$ for the controls. These means did not differ significantly.

4-Choice reaction time $(R T)$ One patient was unable to perform this task because of motor impairment (bilateral upper-limb weakness and ataxia). The mean RT of the remaining 18 patients was $551(105 \cdot 3) \mathrm{ms}$, as opposed to $435(44.5) \mathrm{ms}$ in the case of the controls. The $116 \mathrm{~ms}$ difference between these means was significant $(t 22.6=4.32, \mathrm{p}<0.0005)$, and the variances between the two groups also differed significantly $(F 17 / 18=5 \cdot 60, p<0.01)$. The mean RT of the 16 subjects in whom P3 latency was determined was $532(96.5) \mathrm{ms}$. This mean also differed reliably from that of the controls $(t 20.3=3.73, p<0.005)$, as did its associated variance $(\mathrm{F} 15 / 18=4 \cdot 70, \mathrm{p}<$ 0.05 ). Inspection of the individual data (fig 3 ) revealed that four patients (patients 4, 15, 10 and 16) appeared to form an outlying group. When these patients were dropped from the analysis the mean of the remainder was reduced to $506(65.2) \mathrm{ms}$; this was still reliably different from the mean of the controls $(t 21 \cdot 6=3 \cdot 51$, $\mathrm{p}<0.005)$.

Errors on this task (as defined by depression of an unilluminated button) were too infrequent to subject to analysis (mean of 0.33 for the patients, and 0.37 for the controls).

Relationship between measures For each group, correlations were computed between the three measures of "processing speed": N2 and P3 latency, and 4-Choice RT. In neither group was there any significant correlation between 4-choice $\mathrm{RT}$ and either $\mathrm{N} 2$ or P3 latency. The correlation between N2 and P3 latencies was also non-significant in the control group, but did not attain significance in the patients $(r 14=$ $0.565, \mathrm{p}<0.05$ ).

More informally, it is clear from fig 3 that there is little correspondence even between those patients belonging to the extremes of the distributions of each of the three latency measures, with the possible exception of patient 6 , who shows the shortest or second shortest value on all three measures. It is also noteworthy that patients 10 and 16 feature in the extremes of both the N2 and 4-Choice RT distributions (neither contributed a P3 latency). On the other hand patient 2 , who belongs to the extreme of the N2 and P3 distributions, was the fourth fastest performer among the patients on the 4-choice RT task!

Relationship to severity of injury Using post traumatic amnesia (PTA) duration as an overall measure of severity of injury, the CHI patients were categorised into three groups according to the scheme of Brooks. $^{25}$ Four patients had PTA durations of less than 7 days, 10 had durations of $8-14$ days, and 5 had durations of 15-28 days. As can be seen from fig 3, there was no systematic relationship between those categories and any of the three measures of "efficiency" of information-processing. 


\section{Discussion}

The principal ERP findings in this study can be summarised as follows: N1 latency and amplitude did not differentiate $\mathrm{CHI}$ patients from controls. N2 latency to targets was longer in the patients, and N2 amplitude was larger, particularly in response to target stimuli. Finally, although the amplitude of P3 from the patients was smaller, P3 latency was not significantly different from that of the controls.

The similarity of the $\mathrm{N} 1$ component in patients and controls indicates that at least some of the cerebral mechanisms underlying the generation of ERP components were intact in the patient group. This is important for two reasons: firstly, it means that those features of the ERPs that did distinguish patients and controls were not simply indexing some aspecific dysfunction of ERP generator systems occurring in CHI individuals. Secondly, it has been suggested that the amplitude of the vertex $\mathrm{N} 1$ reflects, at least in part, the general level of "arousal". ${ }^{26}$ It this is so, then the present data suggest that no differences in arousal existed between the patients and controls in this study, at least during the oddball task. This is consistent with data from other sources suggesting that the behavioural problems experienced by $\mathrm{CHI}$ patients are not attributable to "under-arousal".

In contrast to previous studies, ${ }^{1820}$ we found no evidence of a delay in $\mathrm{P} 3$ latency in the $\mathrm{CHI}$ patients. This negative result may reflect the employment in the present study of less severely injured patients than in previous work. Alternatively, it could reflect differences in task and procedure between the present and previous studies. This second alternative seems unlikely in view of the fact that the studies reporting longer P3 latencies in $\mathrm{CHI}$ patients ${ }^{1820}$ employed tasks which differed considerably from one another. The selective attention task employed by Curry ${ }^{20}$ required subjects to make RT responses to low probability targets presented in a designated ear. In contrast, Campbell et al ${ }^{18}$ employed an auditory oddball task very similar to that used in the present study, with the requirement to silently count target tones. In view of the positive findings in relation to N2 latency (see below), it is arguable that P3 latency may not be the most sensitive ERP sign of "speed of processing" in the oddball task. A similar dissociation between N2 and P3 latency has recently been reported by Brecher, Porjesz and Begleiter, ${ }^{27}$ who compared ERPs from schizophrenic patients and controls in a visual oddball task. As in the present case, the latency of N2 (measured in that experiment at $\mathrm{Oz}$ ), but not $\mathrm{P} 3$, was slower in the patient group. We do not wish to imply that this finding is suggestive of similar underlying pathology in $\mathrm{CHI}$ and schizophrenic populations. However, it serves to emphasise the fact that it may be unwise to conclude, on the basis of negative findings with respect to $\mathrm{P} 3$ latency, that a clinical group does not exhibit a deficit in stimulus categorisation time.

As in previous studies, the $\mathrm{CHI}$ patients showed smaller P3s than controls. This result must be interpreted cautiously, however, as it could simply reflect increased latency jitter among the individual trials making up the patients' ERPs. Thus far, no study has employed a latency correction procedure to investigate this possibility, and until this is done the P3 amplitude data will remain equivocal.

The findings concerning the $\mathrm{N} 2$ component are also consistent with previous work. ${ }^{1920}$ As noted above, it seems likely that the latency of this component is associated with the time required to categorise the eliciting stimulus. Thus, the delay in this component in the head-injured patients implies a dysfunction in this process in addition to "later" ones, such as response selection, etc. This supports previous suggestions along similar lines derived from behavioural work employing "additive-factors" logic to decompose the sources of variance contributing to RT in CHI patients. ${ }^{28}$ Such logic is, however, open to question, ${ }^{29}$ and the use of a "real-time" technique able to identify an "early" information-processing deficit provides valuable converging evidence. Thus, the ERP evidence is inconsistent with the idea that the slowness exhibited by patients on RT tasks is entirely the result of inefficiency in "late" processes such as response selection and execution.

In view of the fact that it was the patient group that showed the largest N2 amplitudes, it seems unlikely that differential latency jitter played a part in producing group differences in this variable. However, it is possible that the larger $\mathrm{N} 2$ observed in the $\mathrm{CHI}$ patients resulted simply from overlap with a smaller P3. This possibility seems unlikely because the differences in P3 amplitude between patients and controls do not differ significantly across the scalp, yet the group differences in $\mathrm{N} 2$ are maximal at $\mathrm{Fz}$. If these differences in $\mathrm{N} 2$ had resulted from the influence of the P3 component, they would have had the same scalp distribution as the group differences in the amplitude of P3, that is, they would have been of equal magnitude at the three midline electrodes, rather than frontally distributed.

In a series of auditory oddball tasks, Fitzgerald and Picton $^{12}$ observed changes in the amplitude of N2 as a function of the difficulty of the target/non-target discrimination. They considered these data to be highly suggestive of an association between $\mathrm{N} 2$ amplitude and the allocation of "cognitive effort," such that stimuli whose processing demanded greater effort elicited larger N2s. A similar interpretation of the fronto-central N2 has also been put forward by Näätänen and Picton, ${ }^{13}$ who argued that it reflects, in 
part, the conscious allocation of attentional resources to stimuli indicated as salient by pre-attentive processes. Within this framework, the larger N2s in the patients might be indicative of the greater levels of effort required by this group to perform the task adequately. This would be predicted by the "copinghypothesis" of Van Zomeren et al, ${ }^{7}$ which states that as a result of deficient information-processing, $\mathrm{CHI}$ patients can cope with task demands only by the allocation of excessive cognitive effort. The present data suggest that this may be so even in a task as undemanding as auditory oddball detection.

Finally, it should be noted that although two of the three measures of "processing speed" used in this study clearly discriminated $\mathrm{CHI}$ from control subjects (that is, N2 latency and 4-choice RT), these were uncorrelated in both groups, and neither measure was obviously associated with severity of injury as assessed by PTA duration. The lack of association between N2 and 4-choice RT must undoubtably have been contributed to by the (unknown) intrinsic level of error associated with these measures. However, it probably also reflects the fact that 4-choice RT is determined by a multiplicity of interacting processes (deficits in any one of which will contribute to delayed responding), and only a limited number of these are reflected by $\mathrm{N} 2$ latency. $\mathrm{CHI}$ patients exhibit abnormalities in these latter processes; it remains to be determined how important these abnormalities are in accounting for the wide range of psychological deficits found in these patients.

We thank Mr J D Miller, Department of Neurosurgery, Western General Hospital, Edinburgh, for access to patients under his care. This research was supported by the Medical Research Council and the Mental Health Foundation.

\section{References}

1 Mandelberg IA. Cognitive recovery after severe head injury. 2. The Weschler Adult Intelligence Scale during post-traumatic amnesia. J Neurol Neurosurg Psychiatry 1975;38:1127-32.

2 Mandelberg IA. Cognitive recovery after severe head injury. 3. WAIS verbal and performance IQs as a function of posttraumatic amnesia duration and time from injury. $J$ Neurol Neurosurg Psychiatry 1976;39:1001-7.

3 Mandelberg IA, Brooks DN. Cognitive recovery after severe head injury. 1. Serial testing on the Weschler Adult Intelligence Scale. J Neurol Neurosurg Psychiatry 1975;38:1121-6.

4 Brooks DN. Long- and short-term memory in head-injured patients. Cortex 1975;11:329-40.

5 Levin HS, Grossman RG, Rose JE, Teasdale G. The long-term neuropsychological outcome of closed head injury. $J$ Neurosurg 1979;50:412-22.

6 Van Zomeren AH, Deelman BG. Differential effects of simple and choice reaction after closed head injury. Clin Neurol Neurosurg 1976;14:64-70.

7 Van Zomeren AH, Brouwer WH, Deelman BG. Attentional deficits: the riddles of selectivity, speed and alertness. In Brooks N, ed. Closed Head Injury. Psychological, Social and Family Consequences. Oxford: Oxford University Press, 1984:74-107.

8 Gronwall D, Sampson H. The Psychological Effects of Concussion. Aukland: Aukland University Press, 1974.

9 Ewing R, McCarthy D, Gronwall D, Wrightson P. Persisting effects of minor head-injury observable during hypoxic stress. $J$ Clin Neuropsychol 1980;2:147-55.

10 Donchin E, Ritter W, McCallum WC. Cognitive Psychophysiology: the endogenous components of the ERP. In: Callaway E, Tueting P, Koslow SH, eds. Event-Related Brain Potentials in Man. New York: Academic Press, 1978:349-441.

11 Pritchard WS. Psychophysiology of P300. Psych Bull 1981;89:506-40.

12 Fitzgerald PG, Picton TW. Event-related potentials recorded during the discrimination of improbable stimuli. Biol Psychol 1983;17:241-76.

13 Näätänen R, Picton TW. N2 and automatic versus controlled processes. In: McCallum WC, Zappoli R, Denoth F, eds. Cerebral Psychophysiology: Studies in Event-Related Potentials. Amsterdam: Elsevier, 1986:169-86.

14 Ritter W, Simson R, Vaughan HG. Event-related potential correlates of two stages of information-processing in physical and semantic discrimination tasks. Psychophysiol 1983;20:168-79.

15 Johnson R. A triarchic model of P300 amplitude. Psychophysiol 1986;23:367-84.

16 McCarthy G, Donchin E. A metric for thought: a comparison of P300 latency and reaction time. Science 1981;211:77-80.

17 Magliero A, Bashore TR, Coles MGH, Donchin E. On the dependence of P300 latency on stimulus evaluation processes. Psychophysiol 1984;21:171-86.

18 Campbell, K, Houle S, Lorrain D, Deacon-Elliot D, Proulx G. Event-related potentials as an index of cognitive functioning in head-injured outpatients. In: McCallum WC, Zappoli R, Denoth F, eds. Cerebral Psychophysiology: Studies in EventRelated Potentials. Amsterdam: Elsevier, 1986;486-8.

19 Curry SH. Event-related potentials as indicants of structural and functional damage in closed head injury. In: Kornhuber $\mathbf{H H}$ Deeke L, eds. Motivation, Motor and Sensory Processes of the Brain: Electrical Potentials, Behaviour and Clinical Use. Amsterdam: Elsevier 1980:507-15.

20 Curry SH. Event-related potentials as a tool for assessment of functional disability and recovery following closed head injury. Unpublished PhD Thesis, University of Bristol 1983.

21 Buschke H, Fuld PA. Evaluating storage, retention and retrieval in disordered memory and learning. Neurology 1974; 24:1019-25.

22 Stephenson WA, Gibbs FA. A balanced non-cephalic reference electrode. Electroencephalogr Clin Neurophysiol 1951;3: 237-40.

23 Keselman HJ, Rogan JC. Repeated measures F tests and psychophysiological research: controlling the number of false positives. Psychophysiol 1980;17:499-503.

24 Ferguson GA. Statistical Analysis in Psychology and Education. Sth Edition. New York: McGraw Hill 1981.

25 Brooks DN. Wechsler memory scale performance and its relationship to brain damage after severe closed head injury. $J$ Neurol Neurosurg Psychiatry 1976;39:593-601.

26 Näätänen $R$. Selective attention and evoked potentials in humans-a critical review. Biol Psychol 1975;2:237-307.

27 Brecher M, Porjesz B, Begleiter H. The N2 component of the event-related potential in schizophrenic patients. Electroencephalogr Clin Neurophysiol 1987;66:369-75.

28 Stokx LC, Gaillard AWK. Task and driving performance of patients with a severe concussion of the brain. J Clin Exp Neuropsychol 1986;8:421-36.

29 McClelland JL. On the time relations of mental processes: an examination of systems of processes in cascade. Psychol Rev 1979;86:287-330. 